Revista Iberoamericana, Vol. LXXIV, Núm. 222, Enero-Marzo 2008, 1-

\title{
EL EXTREMISMO DE LA LUCIDEZ: SAN FERNANDO VALLEJO
}

\author{
POR \\ Gastón Alzate \\ California State University
}

\begin{abstract}
Este es uno de los peores conflictos del mundo, una de las peores crisis humanitarias, tienen casi dos millones de desplazados que ponen al país a nivel de Angola, el Congo y Sudán. Tiene una de las tasas de inequidad social más altas del mundo, de concentración de riqueza más altas del mundo. Lo que no entiendo es cómo la tremenda inteligencia y capacidad en la clase alta y media de este país, no hace entender que se requieren profundas reformas.

James Lemoine Delegado de la ONU en Colombia El Espectador, 18 de mayo de 2003
\end{abstract}

Los escritos de Fernando Vallejo describen con cierto deleite el espectáculo de las derrotas políticas tanto colombianas como de la historia occidental. En sus textos, las miserias del hombre y sus fracasos son una condición inexorable que se asume como el fatum de toda empresa colombiana y latinoamericana. El autor no encuentra objeto a su destino humano diferente al de su propia obra, de la que a su vez no deja de desconfiar. Su actitud es completamente subjetivista y sus soluciones políticas corresponden a un clima intelectual asfixiante que gira alrededor de narraciones autolimitadas hasta el extremo: un narrador homosexual en primera persona, iracundo, viejo, erudito y contradictorio que habla con exabruptos y en un lenguaje local; un narrador que cuenta la historia de su familia y constantemente amenaza al lector con morirse o estar muerto, o con dejar la literatura. Este aspecto podría tener resonancias con la "muerte del autor" que propugnaba Roland Barthes; sin embargo, Vallejo va un paso más allá, pues se refiere a la muerte física o literal del autor.

A mi entender, la obra escrita de Vallejo es, en parte, una respuesta estética y ética a la desesperanza producto de la polarización extrema del conflicto social y político de la cultura colombiana. Sin querer reducir su obra a un resultado mecánico de estas condiciones, sino, por el contrario, buscando aportar un enfoque necesario para contribuir a la exposición de su enorme complejidad, me centraré en la relación entre dicho trasfondo y su pensamiento, que ha sido tildado de reaccionario y aún extremista; asimismo consideraré el éxito de la novela La virgen de los sicarios con respecto al contexto colombiano; para finalmente 
detenerme en cómo esa marginalidad no sólo encarna un homenaje a Jean Genet, sino que logra concretar una difícil confluencia de ética y literatura. Vallejo logra distanciarse con maestría tanto de la simpleza y esterilidad de un mero discurso ideológico o contestatario, como de un hueco ejercicio de esteticismo lingüístico.

Pese a que la obra de Vallejo ha sido estudiada desde una amplitud de puntos de vista (el espacio urbano de Medellín, la homosexualidad y el homoerotismo, el Bildungsroman, el narcotráfico y el sicariato como expresiones de marginalidad, el lenguaje local, los topos del infierno, la desacralización y el apocalipsis, y la posmodernidad, entre otros), lo que me ha animado a considerarla bajo la aparente paradoja extremismo/lucidez ha sido la posibilidad de hacer una lectura global de su pensamiento. Teniendo en cuenta las obvias similitudes entre el escritor colombiano y el francés Jean Genet (que van más allá de la imitación, ya que ambos escritores poseen su propio estilo) esta comparación me permitirá afinar mi análisis de la obra de Vallejo como respuesta ética y estética frente a su propia cultura.

Para iniciar mi aproximacion me enfocaré en los estudios críticos más relacionados con el tema que nos ocupa. Daniel Balderston ha realizado un acercamiento al estudio de la ética en la obra de Vallejo desde el punto de vista de la sexualidad, comparándolo con Marcel Proust y discutiendo este tema desde las problemáticas tanto de la prostitución homosexual como de la criminalidad que la narración autobiográfica implica. Mi propósito aquí es paralelo pero algo diferente. Me interesa la postura ética del autor en relación con la ideología y con la historia contemporánea colombiana. Voy a partir de algunas ideas ya expuestas por algunos investigadores sobre el fracaso del proyecto moderno colombiano, especialmente en lo referido a la ideología reaccionaria y a la historia de la mentalidad colombiana. En pocas palabras, éste se refiere al hecho de que Colombia posee una peculiaridad idiosincrática: la postergación de una vivencia plena de la modernidad (Jaramillo Vélez). Esta primera premisa se vería reflejada en la violencia como consecuencia de esa intolerancia. Una posible genealogía en esta dirección fue realizada por el historiador francés Daniel Pécaut quien propone para Colombia el término paramodernidad, ya que la cultura ha favorecido una modernidad negativa que ha asumido muy ambigua y desigualmente las consecuencias sociales, económicas y políticas de la modernidad. Basado en Jaramillo Vélez y Pécaut, Jaime Alejandro Rodríguez ha desarrollado una investigación de la narrativa colombiana desde la historia de las mentalidades. Por ejemplo, siguiendo la evolución literaria del personaje protagonista de la violencia en relación con los distintos experimentos de modernización sociopolítica del país, Rodríguez ha estudiado tres tipos de protagonistas: el asesino, de los años cincuenta, Cóndores no entierran todos los días, de Gustavo Álvarez Gardeazabal; el guerrillero (o el bandolero), Las muertes de Tirofijo, de Arturo Alape; y el sicario, La virgen de los sicarios, de Fernando Vallejo (ver "Pájaros, bandoleros y sicarios: para una historia de la violencia en la narrativa colombiana”).

Como parte de esa paramodernidad, propongo que pueden rastrearse los orígenes de un pensamiento contemporáneo que cuestiona los avances y el supuesto desarrollo de la sociedad colombiana, y que no coincide con los consabidos ideales de izquierda ni de derecha. En este sentido me es de utilidad también lo investigado por Mauricio Galindo Hurtado en su estudio sobre el escritor colombiano Nicolás Gómez Dávila, pues en él Galindo Hurtado hace un recuento de las ideas reaccionarias que llegaron a América desde las luchas de 
independencia, específicamente a Colombia, y que abiertamente declararon su desprecio por la democracia. Aquí habría que hacer una precisión: hay una distancia ideológica considerable entre Gómez Dávila analizado por Galindo, y el filósofo Jaramillo Vélez, ya que para Gómez Dávila el espíritu democrático es una aberración de los tiempos, que marca el descenso final hacia la decandencia cultural de Europa, y para Jaramillo Vélez es el inicio de una modernidad que nunca pudo darse en Colombia. Sin embargo, podemos decir, siguiendo a Galindo Hurtado, que ambos escritores desde puntos ideológicos opuestos cuestionan el statu quo, específicamente las diversas constituciones que dieron inicio a una república producto de un desarraigo muy profundo de la vieja Europa. Es así como próceres e intelectuales criollos latinoamericanos encontraron la ilusión necesaria para desarrollar sus ambiciones políticas en los triunfos liberales en Francia y en los Estados Unidos de finales del siglo XVIII, sin embargo no lograron concebir regímenes que tuvieran relación con las condiciones reales de sus países, tanto en lo político como en lo económico. Como consecuencia de ello tanto para pensadores de formación marxista como Jaramillo Vélez o de ideología conservadora como Gómez Dávila, España no ha representado realmente ningún ideal de civilización.

Ahora bien, ¿qué tiene que ver lo expuesto anteriormente con Fernando Vallejo? En primer lugar que las definiciones reaccionario/progresista o conservador/marxista a la manera como comúnmente las usamos poseen en este trabajo otro carácter. Y en segunda instancia nos muestra que la cultura colombiana ya ha elaborado desde la filosofía un pensamiento paralelo o similar al de Vallejo, aunque con diferencias que trataremos de estudiar. Por ejemplo: en el discurso de inauguración del Primer Congreso de Escritores Colombianos, pronunciado el 30 de septiembre de 1998 en el auditorio de Comfama, en Medellín, Fernando Vallejo se acerca a esta posición, aunque lo hace desde la virulencia y la particular voz de su personaje literario y alter ego:

Ya va para doscientos años que nació esto, un día en que se quebró un florero. ¿Lo quebraron los criollos? ¿Lo quebraron los peninsulares? Unos y otros lo quebraron puesto que eran unos mismos: tinterillos de corazón en busca de puesto. Acto seguido les declaramos la guerra de independencia y se la ganamos. ¿Pero independencia de qué? ¿De quién? ¿Por qué? ¿De España? España era eso: los tinterillos, las estampillas, el papel sellado. Pues los tinterillos con sus estampillas y su papel sellado han pesado desde entonces sobre nosotros y se han parrandeado nuestro destino. Nosotros lo hemos permitido, nosotros les hemos dejado hacer, la culpa es nuestra. ¡Cuánta tinta no ha corrido por este país en esos doscientos años en constituciones y plebiscitos, en ordenanzas y decretos y leyes! Casi tanta como sangre. ¿Y para qué? (http:// www.revistanumero.com/20bicefa.html)

Teniendo en cuenta lo dicho anteriormente, voy a centrarme en un momento muy particular de la historia de Colombia, considerando el pensamiento de Vallejo como una lúcida construcción estética que corresponde a la imposibilidad de alcanzar el proyecto burgués moderno en Colombia. Este acontecimiento es el asesinato del líder liberal Jorge Eliécer Gaitán. La figura particular del líder liberal y su asesinato son menos importantes en nuestro estudio que las dificultades y contradicciones del sistema mismo para intentar falsamente escapar a las estructuras socioeconómicas, religiosas y de raza del pasado colonial. 
En mi estudio de Vallejo parto del magnicidio de Gaitán como una de las primeras frustraciones contemporáneas de las fuerzas progresistas y de centro político por introducir elementos de representación democrática en el sistema colombiano. Este fracaso políticoexistencial del país va a tener su repercusión en el orden cultural y literario de todo el siglo xx y lo que llevamos del xxı, ya que la sociedad en su conjunto será arrastrada por una dinámica de eliminación de todos los aspectos moderados de la cultura. Igualmente producirá proyectos culturales tan destacados e irrepetibles como la revista Mito (1955-1962) fundado por el poeta Jorge Gaitán Durán y en el que participaron Hernando Valencia Goelkel, Pedro Gómez Valderrama, Álvaro Mutis y Gabriel García Márquez, entre otros.

Aunque Vallejo es de la generación siguiente a los autores mencionados, no podrá escapar al tema de la violencia, un período de represión y guerra sucia que, según los cálculos más conservadores, dejó más de 300.000 muertos. Igualmente, Vallejo establecerá los vínculos entre la violencia del pasado y la del presente, ya que señalará en su obra cómo el extremismo actual de la sociedad colombiana (paramilitares vs. guerrilla), tiene indudables semejanzas con la dinámica de la violencia de esa época (conservadores vs. liberales). En el mencionado Primer Congreso de Escritores Colombianos, Vallejo describe la época de "la violencia” de la siguiente forma:

$\mathrm{Y}$ para que no digan que soy un calumniador y que les estoy poniendo a quienes no debo los calificativos que no debo, y que en un congreso de escritores, y justamente el primero que se celebra en Colombia, estoy usando mal las palabras, les voy a recordar unos nombres: El Dovio, Fresno, Irra, Salento, Armero, La Línea, Letras, Icononzo, Supía, Anserma, Cajamarca, El Águila, Falan. [...] ¿Qué? ¿Nunca ocurrieron? Centenares de campesinos decapitados, extendidos en fila por el suelo con las cabezas asignadas por manos caritativas a los cuerpos a la buena de Dios. ¡Qué! ¿Colombia ya los olvidó? ¿Es que con tanto muerto le entró el mal de la desmemoria y se le borró la historia? A mí no. Pues esos genocidios se cometieron en nombre de los principios irrenunciables del gran partido conservador o de los principios irrenunciables del gran partido liberal, según fuera la filiación de los asesinos y del pueblo de los muertos. Poquito después los dos partidos se pusieron de acuerdo, crearon el Frente Nacional y se repartieron los puestos. ¿Y los muertos qué? ¿Y los principios qué? ¿No dizque eran irrenunciables? Si eso no es infamia, entonces yo no sé qué quieren decir aquí las palabras.

Como afirma el escritor colombiano, lo que se ha llamado en Colombia el Frente Nacional ocurre inmediatamente despúes del asesinato de Gaitán y ordena no sólo la alternancia en el poder ejecutivo entre los dos partidos oficiales (conservador y liberal), sino su paridad numérica en el legislativo durante dieciséis años (1960-1976). Las consecuencias del Frente Nacional fueron muy negativas para la cultura ya que éste diluyó las diferencias ideológicas entre los conservadores y los liberales, y legitimó la exclusión de las nuevas fuerzas políticas al crear alianzas basadas en intereses económicos inmediatos. Igualmente permitió la politización de todas las ramas del Estado y agudizó el grave problema de la falta de transparencia en el sector público. Prácticamente se le puede culpar de haber iniciado esa dinámica de exclusión física y sistemática de la oposición. 
Usaré el asesinato de Gaitán como un acontecimiento que abre la puerta a la apatía y al rechazo contemporáneo por la participación política, aunque, como los conocedores del tema colombiano podrán imaginar, existen un número bastante grande de acontecimientos violentos similares al asesinato de Gaitán. Tal vez el que más atañe a nuestro estudio es la eliminación sistemática e individual por fuerzas de extrema derecha de líderes comunitarios, sindicalistas, periodistas, artistas e intelectuales colombianos del centro político, el recrudecimiento de las acciones militares contra poblaciones indefensas por parte de la guerrilla (1985-2006), al igual que la desmovilización de los “paras” (narco-para-militares) por parte del gobierno de Uribe Vélez, llevada a cabo a cambio de penas irrisorias y sin compensación alguna para las víctimas de las masacres por ellos perpetradas, actualmente en proceso (2003-2006). Vale aclarar que el poderío de los paramilitares en varias zonas del país, que es ejercido incluso desde curules en el congreso de la República como se ve en los lazos ampliamente documentados entre políticos y paramilitares, no ha mermado a pesar de dicha desmovilización.

El ÚlTimo gRAmÁtico de Colombia

No se nos puede ir la mano en el incremento del salario mínimo porque sería injusto con los desempleados.

Alberto Carrasquilla, ministro de Hacienda Revista Semana

4 de diciembre de 2005

Para Fernando Vallejo el grado de cinismo de la cultura colombiana ha llegado a un estado en el que la palabra y el lenguaje han dejado de cumplir su sentido más primario. Ya no significan. El resumen que he intentado en este ensayo sobre los antecedentes ideológicos e históricos en el que Fernando Vallejo desarrolla su obra literaria puede servir para entender, grosso modo, por qué para Vallejo Colombia es un país en el cual las instituciones literarias, religiosas y políticas conviven entrelazadas y se retroalimentan en su alto estado de corrupción y ensimismamiento. Las tres instituciones son igualmente pomposas y todas contribuyen y apoyan de algún modo la situación de violencia y desigualdad social que pervive a través de la historia contemporánea, pero sobre todo el gran abismo entre la realidad y la palabra, y por consecuencia entre realidad y literatura.

En su obra literaria Vallejo escribe en la primera persona del singular como una manera desesperada de alcanzar una sinceridad absoluta del lenguaje. Hay en Vallejo un hastío de la literatura en tercera persona pero también de la existencia en tercera persona. La primera persona del singular para él es un principio básico de desenmascaramiento. El cinismo del lenguaje cotidiano no le da al escritor otra alternativa que la construcción de un personaje tan desvergonzado y cínico como la realidad misma. En La virgen de los sicarios, como en casi todos sus libros, encontramos que el protagonista es un gramático, escritor homosexual, iconoclasta, que vuelve a su ciudad natal, Medellín, para morir. Después de haber vivido por treinta años en el extranjero el escritor se encuentra con que su ciudad, la ciudad de su niñez, está dominada por un tipo de violencia muy diferente a la de su infancia. En un burdel 
de muchachos jóvenes, encuentra a Alexis, un joven de dieciséis años. Tanto en la película dirigida por el francés Barbet Shroeder (quien vivió en Colombia en su infancia), como en la novela, la construcción social de la masculinidad para muchos jóvenes colombianos, sea esta heterosexual u homosexual y aunque muchos se nieguen a reconocerlo, está mediatizada por las armas, por el uso o destreza de ellas, y por el número de muertos ocasionados con ellas. De allí que en la película (con guión de Vallejo) Alexis se cubre el sexo con “el fierro” como un símbolo de esta construcción simbólica masculina. Este es un elemento que muchas veces escapa a los análisis sociales y políticos, o no se le da la debida importancia, tanto para analizar la violencia en el pasado como en el conflicto presente. Fernando Vallejo también apunta con su crítica mordaz a un elemento de la cultura colombiana y latinoamericana, y es la doble moral implícita en el hecho de que solamente aquel que no ejerce el rol masculino en las relaciones homosexuales es considerado o percibido como homosexual. Por eso al principio de la cinta el actor que personifica al escritor dice irónicamente refiriéndose a él mismo: “Cómo va a ser marica un tipo que se ha acostado con mil muchachos”. En la historia Alexis procede de los barrios populares y forma parte de un grupo de asesinos que matan a sueldo. En esta ciudad de caos y odio, donde las deudas de sangre pasan de hermanos a hermanos y de amigos a amigos, surge el topos de un amor condenado de antemano por la realidad. Cuando Alexis es fatalmente herido y asesinado Fernando se ve en la búsqueda de su asesino en los barrios más bajos. En lugar del asesino encuentra a Wilmar, quien posee un parecido muy grande con Alexis. ${ }^{1}$

El autor no intenta suplantar sus voces, no intenta hacer una literatura testimonial (Manzoni), no denuncia ni intenta redimir. Construye, en cambio, un universo de compleja belleza, paradójicamente mucho más humano -incluso en lo descarnado- que el de la supuesta "gente de bien", objeto de las variadas imprecaciones del personaje-narrador contra las mujeres que paren como vacas, los prelados de la Iglesia que no son más que travestis, un cobarde Libertador Simón Bolívar y muchos otros símbolos de la nación, la familia patriarcal-simbolizada en la reproducción-o la religión oficial. Como bien afirma María Mercedes Jaramillo en su excelente artículo "Fernando Vallejo: desacralización y memoria”,

Las generalizaciones irreverentes y los exabruptos tienen como objeto socavar convenciones ideológicas falaces en sociedades patriarcales que han mitificado la maternidad y la proliferación como ideales a seguir y que realmente buscan reforzar la familia, la propiedad y el statu quo. (412)

El relato de La virgen de los sicarios es profundamente provocador no sólo por la manera como trabaja el humor negro sobre el que va revelándonos los detalles más significativos de la cultura narco-homosexual adolescente de Medellín, sino por los estados de ternura y lirismo que los personajes alcanzan en medio de la violencia más atroz.

\footnotetext{
${ }^{1}$ La poeta Alejandra Pizarnik decía en un hermoso poema de una línea: "La rebelión consiste en mirar una rosa hasta pulverizarse los ojos”. Los sicarios maricones y adolescentes de Vallejo en La Virgen de los sicarios son esas rosas.
} 
A pesar de que La virgen de los sicarios no es la primera novela en confrontar el impacto del narcotráfico en la sociedad colombiana (Leopardo al sol-1993- de Laura Restrepo es ligeramente anterior), ni es la primera que toca el de la homosexualidad y el narcotráfico en abierto conflicto con los arraigados principios morales colombianos (El divino-1986- de Álvarez Gardeazábal también es anterior), podemos afirmar que con esta novela Vallejo tocó significativamente el tejido simbólico contemporáneo de la cultura colombiana, impactando directamente al campo editorial, y especialmente la percepción internacional del país, ya que, como afirmó el crítico Rafael Gutiérrez Girardot, en Colombia “ya no se crean novelas por creación sino para vender, y lo que se vende son los temas más actuales, la violencia en Colombia, la prostitución, etc.” (Mogollón 361). Valga aclarar que este crítico, uno de los más lúcidos estudiosos de la literatura colombiana, no culpa al escritor por las consecuencias de su obra. Fuera de las de Restrepo y Álvarez Gardeazábal, hay, desde luego, otras novelas colombianas del mismo período con temáticas paralelas, como muestra José Cardona López en su artículo "Literatura y narcotráfico”. Las más significativas serían Cartas cruzadas (1995) de Darío Jaramillo Agudelo, Morir con papá (1997) de Óscar Collazos y Fragmentos de amor futuro de Héctor Abad Faciolince (1998). Sea como sea, culpar a los escritores, y en concreto a Vallejo, de la histórica degradación moral y social del país es un completo desatino, pues es más que evidente que La virgen de los sicarios no es una novela escrita para agradar a nadie.

La crítica contra la persona de Vallejo por su amplitud merecería un análisis aparte, bástenos señalar aquí que cuando la novela salió publicada en 1994 la reacción tanto de los críticos como del público en general fue muy dividida. Inmediatamente surgieron los bandos de inquisidores y de apologistas, que hasta el día de hoy no han podido reconciliarse (pese a que los detractores se han ido "calmando" y los apologistas han ido aumentado con los años). Germán Santamaría, prestigioso escritor y periodista, por ejemplo afirmó sobre Vallejo en un artículo titulado ambiguamente "Prohibir al sicario":

Un delirante que le quiere cobrar a toda una nación el no haber podido ser felizmente homosexual en Medellín, como lo proclama en todas sus entrevistas. Es asunto suyo que esa sea su opción física, e incluso es respetable, porque no se trata de discriminar a nadie por su sexualidad. Pero que no sea, por favor, un maricón tan escandaloso. ¡Cálmese! (http://www.revistadiners.com.co/noticia.php3?nt=5125)

El crimen, al parecer no era ser homosexual, sino ser escandaloso, es decir, la homosexualidad está bien siempre y cuando nadie se dé cuenta de ella. El ataque a la disidencia sexual escandalosa de Vallejo intentaba, por un lado, distraer la atención generada por la obra sobre la realidad de la cultura del sicariato y por otro, evitar el tema concomitante e inevitable de la ineptitud del estado colombiano y sus elítes políticas e intelectuales frente a la desintegración social. En consecuencia, aquellos que la defendieron inicialmente fueron comentaristas o intelectuales caracterizados por ser agudos críticos del establishment. Por ejemplo, Antonio Caballero, escritor, periodista y crítico, respondió así a los comentarios de Santamaría: “¿Y por qué quedan en la película, o en la novela original, los antioqueños y los colombianos y todos los demás como 'una manada de...'?[frase de Santamaría en su artículo] Pues porque matan, porque mueren, etc.: en las calles, en las iglesias, en el metro 
de Medellín”. Con ello Caballero coloca el dedo en la llaga de esa suerte de idiosincracia colombiana que está por encima de toda realidad: “quedar bien”, ya que para muchos la preocupación es que otros se den cuenta de que en Colombia hay delincuencia y narcotráfico.

No debe obviarse tampoco en este análisis que la publicación de esta novela coincide también con el crecimiento de editoriales como Norma y Santillana. Estas se establecen o expanden sus casas editoriales en Colombia en los noventa en gran parte debido a que esa década, además de contar con la aparición de una nueva generación de escritores, fue también la de mayores beneficios arancelarios para la industria bibliográfica. La Ley 98 de 1993, llamada "Ley del Libro", facilitó un mercado más abierto debido a los subsidios a la exportación a otros países. Sin menospreciar la labor de difusión de las editoriales dentro de una economía neoliberal (García Canclini, Martín-Barbero), es indudable que el conflicto armado colombiano también ha servido para vender libros. Cabe así darle un sentido bastante literal a la famosa afirmación de Walter Benjamin de que nunca se da un documento de cultura sin que lo sea a su vez de violencia ("Para una crítica de la violencia”).

EL EXTREMISMO DE LA RAZÓN

Ahora bien, el título de este ensayo es “el extremismo de la lucidez”. Vallejo ha sido tachado muchas veces de extremista, nihilista y especialmente de reaccionario. Examinaré en qué consiste este extremismo reaccionario y específicamente qué papel juega esta forma de pensamiento en su visión de la literatura. Para comenzar una aproximación al concepto, parto del ensayista colombiano Hernando Téllez, quien afirma que el escritor reaccionario es "alguien capaz de profesar un conjunto de ideas que niegan la totalidad del sistema en sus dos fases, la comunista y la capitalista” (99). Debido a esta posición ideológica tan particular, las ideas del escritor reaccionario son fácilmente interpretadas como las de una persona resentida con su tiempo y su cultura, "un pensamiento tan descaradamente despectivo de todo lo que signifique modernidad o, con más veras, contemporaneidad" (Torres Duque, http://www.lablaa.org/blaavirtual/publicacionesbanrep/boletin/boleti1/ bol40/bol40uno.htm). En este sentido, además de afirmar la inutilidad de las ideologías o de cualquier posibilidad de acierto de los sistemas filosóficos, el escritor reaccionario es anacrónico, esto es, es un convencido de que la humanidad se dirige inequívocamente hacia atrás, de que la evolución cultural se detuvo en algún punto y lo que vivimos hoy día es una forma de prehistoria.

A las categorías de "inutilidad de las ideologías” y “antimodernidad y anacronismo" se debe añadir una más, proporcionada por el escritor rumano Emil Michel Cioran (1911), para quien lo reaccionario es fundamentalmente lo contestatario, aquello que desconstruye lo tradicional y dominante (ver Creencias y esperanzas de un escéptico). Hago entonces una primera precisión: un reaccionario, de la manera en la cual quiero definirlo en esta investigación, no es necesariamente un antirrevolucionario o una persona religiosa o conservadora que apoya el statu quo. De hecho, el reaccionarismo literario de Vallejo también tiene una dosis anticlerical, pues de alguna manera usa una retórica moral invertida, una suerte de contra-evangelio. En una entrevista que le concedió al escritor mexicano Juan Villoro, este último lo compara con un moralista del xviI, a lo que el colombiano contesta: 
A Voltaire lo educaron los jesuitas, y a mí los salesianos. Y los jesuitas comparados con los salesianos son unas mansas palomas. Yo conozco lo peor de lo peor. Pero mi polémica no es con este Papa [Juan Pablo II], que al fin de cuentas no es más que un pobre diablo que ya por fortuna se va a morir; mi polémica es con Cristo, uno al que tampoco le dio el alma para entender lo que tenía que entender: que los animales también son nuestro prójimo, y no sólo el hombre, que es el más malo de los animales. Y después de Cristo con Mahoma, esa bestia reproductora y lujuriosa. (http:// www.Trazegnies.Arrakis.Es/Fvallejo.html)

Muchos lectores se preguntarán si tal extremismo es sólo una manera de hablar o una particular forma de escandalizar. A ratos el escritor antioqueño parece muy convencido:

El sentido del hombre en la vida es ninguno. No hay ningún sentido, ni del hombre ni de ningún ser vivo en la tierra, puesto que vamos a la muerte y a la nada, a volver a la materia de donde salimos. En cuanto a la religión, ella es muy reciente. Cristo tiene dos mil años, y el ser humano como especie tiene por lo menos siete millones de años. ¿Dónde estaba Dios entonces durante todos esos millones de años en que el hombre estaba sobre la tierra? (Delgado, http://www.clubdelibros.com/ archifernandovallejo2.htm)

A pesar de esta seguridad lapidaria propia del extremista, a veces parece que a Vallejo lo asaltara una duda en forma de nostalgia por el pasado (ver El río del tiempo), por un mundo mítico ya perdido muy cercano a la religión, de allí su pasión por María Auxiliadora como virgen de los sicarios. De modo semejante al Marqués de Sade, Vallejo insulta a Dios porque no existe, porque nunca ha estado y porque nos ha dejado en cambio una iglesia corrupta e hipócrita. Por el contrario, ante la María Auxiliadora de los sicarios colombianos es como si todo el catolicismo se hubiera vaciado de sus impurezas y adquiriera un nuevo sentido, es como si los íconos de la religiosidad popular estuvieran investidos de una nueva y auténtica mitología. Algunas de las claves de esta nostalgia mitológica de Vallejo pueden ser rastreadas en su discurso pronunciado en el IX Festival Internacional de Arte de Cali que el autor tituló “Los difíciles caminos de la esperanza”. Allí la estatua de Cristo Rey, al final del discurso, es un símbolo de lo que podríamos llamar una espiritualidad perdida y súbitamente recuperada en las ruinas de su literatura. Dice Vallejo:

La última finca que tuvo [mi papá] la llamó La Cascada, por una cascada hermosa que tenía, de tres caídas, que se desprendía de una montaña. Y atrás de esa montaña otra montaña, aún más alta, de la que se desprendían otras cascadas, y arriba de la montaña alta, coronándola entre las nubes desde las que se soltaban los más formidables aguaceros, una estatua de Cristo Rey. [...] Pero yo nunca subí. La subida tomaba medio día y yo prefería quedarme abajo estudiando. [...] A ratos ponía el libro a un lado y empezaba a subir con la imaginación por la montaña, saltando de piedra en piedra por sus cascadas rumbo a las nubes desde las que se soltaban los aguaceros, hasta que llegaba a la cima donde estaba, abriendo sus brazos en cruz como para abarcar a Colombia, Cristo Rey. Me paraba delante de la estatua sobre el abismo, abría los brazos como él, y mis brazos se convertían en alas. Entonces me volvía un cóndor y emprendía el vuelo, el más espléndido vuelo sobre mis valles y mis ríos y mis 
montañas, y me iba volando, volando, muy alto, muy alto, donde no me podían alcanzar las balas, contra el cielo azul. (http://www.revistanumero.com/ 24dificiles.htm)

SANTOS, CRIMINALES Y HOMOSEXUALES

Yo soy un santo de nueva cuenta sin la soberbia de la humildad.

Fernando Vallejo Años de indulgencia

Esa estatua abandonada de Cristo Rey, que abre sus brazos poderosos a una Colombia alcoholizada en los humores de la sangre, es -a mi entender- la visión de una religiosidad muy similar a la que Jean Paul Sartre describe en su libro San Genet comediante y mártir sobre la obra del escritor francés Jean Genet. Es más, es casi evidente que Vallejo tuvo como referencia la novela Nuestra Señora de las Flores (1943) de Genet para escribir "La virgen de los sicarios”. Existen también otros parecidos. Genet al igual que Vallejo fue catalogado en su tiempo de reaccionario pese a que la intelectualidad francesa, principalmente de izquierda, lo apoyaba. Mientras estaba en la cárcel, Genet escribió y publicó varios libros, y su creciente prestigio literario movió, especialmente a Cocteau, Simone de Beauvoir y Sartre, a pedir su liberación, que finalmente fue concedida en 1948 por el gobierno francés. La primera novela de Genet fue Nuestra Señora de las Flores, un trabajo autobiográfico de cargado erotismo acerca de la homosexualidad y la vida en los bajos fondos. La obra está escrita por el preso de la celda 426 y exalta la vida de un asesino. La virgen de los sicarios y Nuestra Señora de las Flores comparten el espíritu blasfemo y una construcción simbólica de la masculinidad homosexual que raya en la misoginia. En ambos autores se plasma ese contraste entre el personaje rudo y violento (Genet) e iracundo (Vallejo) que alcanza momentos de ternura en su visión irónica y caricaturesca de lo masculino. Genet utiliza la cultura sexual gay de los jóvenes asesinos franceses como una abierta forma de la ofensa. Vallejo utiliza la cultura sexual gay narcotraficante de los adolescentes colombianos. Vallejo, como Genet, no habla para que lo escuchen, ni escribe para que lo lean. Utiliza las palabras para permanecer en la carencia, para seguir siendo un "muerto social” (el delincuente o el viejo extremista). Como afirma María Mercedes Jaramillo: "El narrador consciente de esta realidad grotesca decide encarnar la fealdad del mundo y sus andanzas se convierten en un inventario de la infamia” (429). En gran medida David W. Foster en Gay and Lesbian Themes in Latin American Writing se había acercado a esta noción de santidad que yo he querido explorar en este artículo en relación a Genet, aunque Foster lo interpreta específicamente como un desafío que el autor colombiano plantea a los códigos morales de la sociedad "sobre la base de compromisos personales más elevados”(127). Foster entiende la disidencia sexual del autor como parte esencial de esa postura ética (154).

Leídos, a pesar suyo, por un público más o menos numeroso, Genet y Vallejo hacen el mal infectando el mundo a mayor escala. Se convierten en objeto literario del horror. Obligan a los otros a verlos como ellos quieren ser vistos y como el lector mismo no quiere ni verlos ni ser visto. Ya no cometen el crimen sino que dan su significado y su interpretación. 
Es éste el verdadero mal que causan a la sociedad: mostrarle el producto que ella ha creado. Vallejo afirma sobre su obra: "Son libros terroristas porque, a fin de cuentas, como no tengo a nada que aferrarme tengo el derecho a burlarme de todo y no hay nada de lo que no me pueda burlar"(Villena Garrido, http://www.lehman.cuny.edu/ciberletras/v13/villenagarrido.htm).

Por su parte, Jean-Paul Sartre afirma que Genet, en Notre-Dame des Fleurs, se muestra sin compasión ni piedad. Sus personajes se ven obligados a amar lo que odian y por ello son mártires, por ello son santos, solitarios, medio locos, casi esquizofrénicos. Genet afirma sobre el santo y el criminal: "Ambos viven en soledad. Si examina [usted] el asunto con detenimiento, ¿no tiene la impresión de que los grandes santos parecen criminales? No existe un lazo visible entre sociedad y santidad. La santidad asusta" ("Interview with Genet", http://www.islaternura.com/APLAYA/NoEresElUnico/gLETRA/Genet/ GenetENTREVISTA.htm).

La idea de Sartre es que cada quien es siempre responsable de lo que se ha hecho de él, aun si no puede hacer nada más que asumir esta responsabilidad (Florián). Sartre piensa que un hombre siempre puede hacer algo de lo que se ha hecho de él. Es la definición que daría Sartre de la libertad: ese pequeño movimiento que hace de un ser social, condicionado por una historia y una sociedad, una persona que no restituye la totalidad de lo que ha recibido; eso es lo que según Sartre hace que Genet haya devenido en poeta, ya que Genet era un criminal. En un caso como el suyo, la libertad no puede ser algo positivo, feliz, ideal. Para Genet, como para Vallejo, la literatura no tiene mucho que ver con el éxito o el triunfo, a pesar de que el colombiano sea un intelectual proveniente de una familia con medios económicos. La literatura, como el gran arte, les abre ciertos caminos que no les habían sido ofrecidos por sus culturas desde el principio de sus existencias.

Para Sartre, como para Vallejo, el lenguaje devela, saca a la luz lo que no hemos visto o lo que queremos ignorar. En ese sentido nombrar, y Vallejo es un experto nombrando, es ya transformar. Sartre afirma: "El lenguaje es una actividad de develamiento. Para mí y para los otros, la palabra hace surgir de la sombra un objeto y lo integra a nuestra actividad general" (43). Puede equipararse el asombro que nos produce el lenguaje de Vallejo a lo que Bernardo Correa, hablando de Sartre, designa como "la pérdida de la inocencia”: ya no hay misterio, no puedo refugiarme en la ignorancia porque lo nombrado salió a la luz y no puedo, por tanto, dejar de verlo, "a menos que quiera, adoptando una conducta de mala fe, eludir mis responsabilidades” (Correa 20). Todo el peso político y ético que soporta el lenguaje literario de Vallejo reside en su capacidad de develamiento, en lo que podría denominarse su carga poética, según la definición que del poeta dio María Zambrano durante su exilio mexicano en Realidad y poesía: "el poeta saca de la humillación del no ser a lo que en él gime, saca de la nada a la nada misma y le da nombre y rostro. El poeta no se afana para que de las cosas que hay, unas sean y otras no lleguen a este privilegio, sino que trabaja para que todo lo que hay y lo que no hay, llegue a ser. El poeta no le teme a la nada” (23). Esa nada en Vallejo es la realidad de un país que vive la ausencia de futuro, la ausencia de Dios, la ausencia de Estado, y sobre todo, la ausencia de esperanza. 


\section{CONCLUSIÓN}

En un país como el colombiano "que se ha preciado de ostentar el descabellado engaño ideológico de hablar el mejor español del mundo" (Cardona López 397) y en donde las costumbres coloniales, como "el quedar bien", se preservan por encima de las masacres y los asesinatos políticos, Vallejo, como se ha señalado ampliamente, siguiendo una tradición contestataria propia de la intelectualidad antioqueña, que incluye escritores como Tomás Carrasquilla, Porfirio Barba Jacob, Fernando González y Gonzalo Arango, realiza la crónica de la devastación de los últimos años de la República de Colombia. Como ellos, utiliza el escándalo, el extremismo y el sarcasmo para sacudir una cultura anquilosada. Vallejo nos presenta un evangelio al revés, donde los asesinos disparan balas rezadas. El telón de fondo de su universo literario es la paradójica contemporaneidad colombiana, el caos social de tres millones de refugiados rurales que en los últimos diez años se han aglomerado en las más precarias circunstancias en las grandes ciudades huyendo de la guerra fratricida, según datos de la Consultoría para los Derechos Humanos y el Desplazamiento y la Conferencia Episcopal de Colombia (véase Arboleda). Como respuesta estética y ética a este dantesco infierno histórico y social (Fernández l'Hoeste), la obra de Vallejo hace suyo ese lugar común, suerte de imaginario fascista colombiano, en el que hablar de temas sociales implica ser comunista y/o apoyar la guerrilla. Pero el extremismo de Vallejo no es político: es el de quien arremete contra todos por igual. Vallejo es el maestro de la injuria como un arte (Marín).

Odiado y amado por artistas, escritores y políticos, la obra de Vallejo es para muchos lectores la música del desconcierto. Su opción de narrar en primera persona asume el riesgo de que algunos críticos y escritores entiendan sus extremismos argumentativos literalmente (mas no literariamente). Como el mismo autor afirma "mis novelas no están escritas para sostener tesis" (Villena Garrido). Como buen reaccionario, en el sentido definido en este artículo, Vallejo interpreta la realidad nacional como la no participación política o ciudadana, y su respuesta literaria es la huida hacia otras realidades estéticas e históricas que se sitúan en el ambiguo territorio de su infancia (Los días azules), de la sexualidad (El fuego secreto) o de la religiosidad popular (La virgen de los sicarios). Todos ellos son espacios míticos marginales que constituyen utopías efímeras y sin futuro. Sin embargo, estas utopías parecen ser en su obra los elementos fundamentales de una desesperanza necesaria para alcanzar la extrema lucidez, la justificación de lo injustificable y en último término, una santidad de nueva cuenta y "sin la soberbia de la humildad".

\section{BibLIOGRAFÍA}

Ágreda, Javier. “Laura Restrepo y su delirio”. Reseñas y críticas literarias. La República (Lima, 27 de septiembre de 2004): s.p. http://agreda.blogspot.com/ 2004_09_01_agreda_archive.html

Álvarez Gardeazábal, Gustavo. El divino. 7 ed. Bogotá: Plaza y Janés, 1987.

Araujo, Helena. “Las hijas y ahijadas de García Márquez”. El Nuevo Dia: Ideas y Libros

(20 de abril de 2003): s.p. http://72.14.203.104/search?q=cache:XcCGxbjuHQsJ:ea.elnuevodia.com 
“¿Imitadoras de García Márquez? Un mimetismo lucrativo”. Feminaria 11/22-23 (1999): 95-100.

Arboleda García, Javier. “En el país hay tres millones de desplazados”. El Colombiano (11 de febrero de 2006): s.p.http://www.elcolombiano.terra.com.co/BancoConocimiento/ E/en_el_pais_hay_tres_millones_de_desplazados.asp?codSeccion=59.

Balderston, Daniel. “Ética y sexualidad en la ficción autobiográfica de Fernando Vallejo”. El deseo, enorme cicatriz luminosa. Rosario: Beatriz Viterbo, 2004. 151-164.

Benjamin, Walter. Para una crítica de la violencia. Buenos Aires: Editorial Leviatán, 1995. Castellanos, Yino. “El amplio horizonte de la razón”. Carta Universitaria, Universidad Nacional de Colombia 13 (2006): s.p. http://www.cartauniversitaria.unal.edu.co

Cano, Luis A. “Metaforización de la violencia en la nueva narrativa colombiana”. Ciberletras 14 (2005): s. p. http://www.lehman.cuny.edu/ciberletras/v14/cano.htm

Cardona López, José . "Literatura y narcotráfico: Laura Restrepo, Fernando Vallejo, Darío Jaramillo Agudelo". Jaramillo et al. 378-407.

Castillo, Carolina. “Colombia: violencia y narración”. Espéculo: Revista de Estudios Literarios 27 (2004): s. p. http://www.ucm.es/info/especulo/numero27/colombia.html

Cioran, Emile. Creencias y esperanzas de un escéptico. Bogotá: Universidad Nacional de Colombia, 2002.

Collazos, Óscar. Morir con papá. Bogotá: Planeta Colombia, 1997.

Corbatta, Jorgelina. "Lo que va de ayer a hoy: Medellín en Aire de tango de Manuel Mejía Vallejo y La Virgen de los Sicarios de Fernando Vallejo”. Revista Iberoamericana 69.204 (2003): 689-99.

Correa, Bernardo. “La lucha con las palabras”. Sartre: cien años. Al margen 15 y 16(2005): 8-21.

Delgado, Manuel. “Declaraciones alarmantes de escritor Fernando Vallejo”. Club de Libros sin fecha: s.p. http://www.clubdelibros.com/archifernandovallejo2.htm

Fernández l’Hoeste, Héctor D. “La virgen de los sicarios o las visiones dantescas de Fernando Vallejo”. Hispania 83/4 (2000): 757-67.

Florián, Víctor. “Estructuralismo versus existencialismo”. Sartre: cien años. Al margen 15 y 16 (2005): 318-23.

Foster, David W. Gay and Lesbian Themes in Latin American Writing. Austin: U of Texas P, 1991.

Galindo Hurtado, Mauricio. "Un pensador aristocrático en los Andes: una mirada al pensamiento de Nicolás Gómez Dávila”. Revista Historia Crítica, Universidad de los Andes 19 (2000): s.p. http://historiacritica.uniandes.edu.co/html/19/ resena_galindo.html

Genet, Jean. "Interview with Genet”. Playboy 4 (1964): s.p. Traducción Isla Ternura, http://www.islaternura.com/APLAYA/NoEresElUnico/gLETRA/Genet/ GenetENTREVISTA.htm

Giraldo, Luz Mery. Narrativa colombiana: búsqueda de un nuevo canon. 1978-1995. Bogotá: Ceja, 2000.

Human Rights Watch. “Informe anual, los sucesos de 2004”. Hrg.com: Informes 2005: s.p. http://www.hrw.org/spanish/inf_anual/2005/colombia.html\#colombia 
Jaramillo Agudelo, Darío. Cartas cruzadas. Bogotá: Alfaguara, 1995.

Jaramillo, María Mercedes. "Fernando Vallejo: desacralización y memoria”. Jaramillo et al. 407-39.

Betty Osorio y Ángela I. Robledo, eds. Literatura y cultura: narrativa colombiana del siglo XX. Vol 2. Bogotá: Ministerio de Cultura, 2000.

Jaramillo Vélez, Rubén. Colombia: la modernidad postergada. Bogotá: Argumentos, Temis, 1994.

Jaramillo Zuluaga, J. Eduardo. "El río del tiempo no desemboca en el mar de Manrique”. Número 3 (1994): 89-91.

“Laura Restrepo y Jorge Franco: el nuevo ‘boom’ de Colombia”. La prensa@: Bolivia (8 de agosto de 2004): s.p. http://166.114.28.115/fondo_negro/20040808/art01.htm

Manzoni, Celina. "Fernando Vallejo y el arte de la traducción”. Cuadernos Hispanoamericanos 651-652 (2004): 45-55.

Marín, Humberto. "En defensa del arte de injuriar”. Número 46 (2005): s.p. http:// revistanumero.com/46/indice.htm

Martínez, Fabio. “Fernando Vallejo: elángel del Apocalipsis”. Boletín Culturaly Bibliográfico 25/14 (1988): 34-41.

Mogollón, Juan Manuel. “Entrevista con Rafael Gutiérrez Girardot”. Literatura: Teoría, Historia, Crítica 6 (2004): 357-67.

Mora, Orlando. "La virgen detrás de cámaras: la relación reveladora entre Vallejo y Schroeder”. El Colombiano: Proyectos, Virgen de los sicarios. s.f.: s.p. http:// www.elcolombiano.terra.com.co/proyectos/virgendelossicarios/detrasdecamaras.htm

Murillo, Javier H. Prólogo. El río del tiempo. Fernando Vallejo. Bogotá: Alfaguara, 1999. 7-18.

“Un huapití para Fernando Vallejo”. Número 16 (1997): 24.

Ospina, Luis. La desazón suprema: retrato incesante de Fernando Vallejo. Documentary, 90 minutos, 2003.

Ospina, William. “No quieren morir, pero matan”. Número 26 (2000): 26-31.

Palau, Carlos. "La virgen de los sicarios”. En rodaje: Magazine (8 de junio de 2003). s.p. http://www.enrodaje.cinecolombiano.com/4virgen_de_los_sicarios_1.htm.

Pécaut, Daniel. Orden y violencia: Colombia 1930-1954, dos volúmenes. Bogotá: CerecSiglo XXI. 1987. Restrepo, Laura. Delirio. Madrid: Santillana Ediciones, 2004.

Restrepo, Laura. Delirio. Madrid: Alfagura, 2004.

El leopardo al sol. Bogotá: Planeta Colombia, 1993.

Restrepo-Gautier, Pablo. "Lo sublime y el caos urbano: visiones apocalípticas de Medellín en La virgen de los sicarios de Fernando Vallejo”. Chasqui 33/1 (2004): 96-105.

Rodríguez, Jaime Alejandro. "Pájaros, bandoleros y sicarios: para una historia de la violencia en la narrativa colombiana”. Revista Universitas Humanística 47 (1999): 105-126.

Rosas Crespo, Elsy. "La virgen de los sicarios como extensión de la narrativa de la transculturación”. Espéculo 24 (2003): s.p. http://www.ucm.es/info/especulo/ numero24/virgen.html

Rueda, María Helena. "Escrituras del desplazamiento. Los sentidos del desarraigo en la narrativa colombiana reciente”. Revista Iberoamericana LXX/207 (2004): 391-408. 
Santamaría, Germán. "Prohibir al sicario”. Diners, mayo 2000. s.p. http:// www.revistadiners.com.co/noticia.php3?nt=5125

Sartre, Jean Paul. La responsabilité de l'écrivaint. París: Verdier, 1998. 41-44.

Suárez, Juana y Carlos Jáuregui. "Profilaxis, traducción y ética: la humanidad 'desechable' en Rodrigo D, no futuro, La vendedora de Rosas y La virgen de los sicarios”. Revista Iberoamericana 199 (2002): 367-392.

Taborda Sánchez, Juan Fernando. “Oralidad y escritura en La virgen de los sicarios de Fernando Vallejo”. Estudios de Literatura Colombiana 3 (1998): 50-56.

Téllez, Hernando. “Confesión de parte”. Bogotá: Ediciones del Banco de la República, 1967. 99.

Torres Duque, Óscar. “Nicolás Gómez Dávila: la pasión del anacronismo”. Boletín Cultural y Bibliográfico 32/40 (1997): s.p. http://www.lablaa.org/blaavirtual/ publicacionesbanrep/boletin/boleti1/bol40/bol40uno.htm

Valencia Solanilla, César. "La virgen de los sicarios: el sagrado infierno de Fernando Vallejo”. Revista de Ciencias Humanas 26 (2001): s.p. http://72.14.203.104/ search?q=cache:c_1jEOReegJ:www.utp.edu.co/ chumanas/revistas/revistas/rev26/ valencia.htm

Vallejo, Fernando. El desbarrancadero. Bogotá: Alfaguara. 2001.

“El monstruo bicéfalo”. Revista Número 20 (1998). s.p. http:// www.revistanumero.com/20bicefa.htm La virgen de los sicarios. Buenos Aires: Alfaguara, 1994.

"Los difíciles caminos de la esperanza”. Revista Número 24 (2002). s.p. http:// www.revistanumero.com/24dificiles.htm

Vásquez, Juan Gabriel. “La mierda y la gramática”. Lateral 87 Marzo 2 (2002): s.p. http:/ /www.lateral-ed.es/revista/foco/087fvallejo.htm

Villena Garrido, Francisco. "La sinceridad puede ser demoledora: conversaciones con Fernando Vallejo. Ciberletras 13(2005): s.p.http://www.lehman.cuny.edu/ciberletras/ v13/villenagarrido.htm.

Villoro, Juan. "Literatura e Infierno: entrevista a Fernando Vallejo”. Babelia Digital (1 de junio de 2002): s.p. http://www.Trazegnies.Arrakis.Es/Fvallejo.Html 
